(C) 2017 IEEE. Personal use of this material is permitted. Permission from IEEE must be obtained for all other uses, in any current or future media, including reprinting/republishing this material for advertising or promotional purposes, creating new collective works, for resale or redistribution to servers or lists, or reuse of any copyrighted component of this work in other works. 


\title{
Variable Structure Control in Natural Frame for Three-Phase Grid-Connected Inverters with LCL Filter
}

\author{
Ramon Guzman, Luis Garcia de Vicuña, Miguel Castilla, Jaume Miret, Member, IEEE and Helena \\ Martín
}

\begin{abstract}
This paper presents a variable structure control in natural frame for a three-phase gird-connected voltage source inverter with LCL filter. The proposed control method is based on modifying the converter model in natural reference frame, preserving the low frequency state space variables dynamics. Using this model in a Kalman filter, the system state-space variables are estimated allowing to design three independent current sliding-mode controllers. The main closed-loop features of the proposed method are: 1) robustness against grid inductance variations because the proposed model is independent of the grid inductance, 2) the power losses are reduced since physical damping resistors are avoided, 3) the control bandwidth can be increased due to the combination of a variable hysteresis comparator with the Kalman filter, and 4) the grid-side current is directly controlled providing high robustness against harmonics in the grid. To complete the control scheme, a theoretical stability analysis is developed. Finally, selected experimental results validate the proposed control strategy and permit illustrating all its appealing features.
\end{abstract}

Index Terms-Grid current control, LCL filter, Sliding mode control, Kalman filter, Voltage sensorless.

\section{INTRODUCTION}

This work has been supported by the European Union Project ELAC2014/ESE0034 and its linked to Spanish National Project PCIN-2015- 001 and also supported by the Ministry of Economy and Competitiveness of Spain under project ENE2015-64087-C2-1R. Recommended for publication by Associate Editor xxx.

Ramon Guzman is with the Department of Automatic Control, Technical University of Catalonia, 08800 Vilanova i la Geltru, Spain (e-mail: ramon.guzman@upc.edu).

Luis Garcia de Vicuña, Miguel Castilla, and Jaume Miret are with the Department of Electronic Engineering, Technical University of Catalonia, 08800 Vilanova i la Geltru, Spain (e-mail: vicuna@eel.upc.edu)

Helena Martn is with the Department of Electric Engineering, Technical University of Catalonia, Barcelona East School of Engineering, 08019 Barcelona, Spain (e-mail: m.helena.martin@upc.edu).

Color versions of one or more of the figures in this paper are available online at http://ieeexplore.ieee.org.

Digital Object Identifier xxxxx
D OWER converters are commonly used in many power applications such as uninterruptible power supplies, unity power factor rectifiers and voltage source inverters (VSI's). The controller design is a difficult task when the converter is equipped with an LCL filter due to its inherent resonance problem, specially in grid connected inverters used in distributed generation where a large set of grid impedance values may affect the system stability [1].

Kalman filter (KF) based-control has been widely used in power electronics [2], where accurate power converter models are considered to estimate the state variables. Unlike these control methods, the model-based control presented in this paper uses a modified statespace model which preserves the low frequency statespace variables dynamics, and allows to design a robust sliding mode control (SMC) in natural reference frame. The use of the SMC technique improves the tracking behaviour and dynamic performances, providing fast dynamic response with high robustness against system parameters variations [3], [4].

The SMC technique was also introduced in a singlephase grid-connected LCL-filtered VSI with interesting properties as fast dynamic response, robustness, and sinusoidal grid currents with low total harmonic distortion [5], [6]. Besides, the use of SMC has been applied to three-phase active power filters in stationary and rotating reference frames [7]. Other relevant works regarding the SMC technique can be found in [8]-[13].

Traditionally, VSIs with LCL filter have been controlled by means of the inverter-side current. Recent references can be found regarding to the control of the grid-side current for single-phase systems [14], [15] or for three-phase systems [16]-[18]. In most of these proposals the use of digital filters is needed in other to implement the control algorithm, and as a consequence the robustness against system parameters variations may be compromised.

Conversely, and as per authors knowledge, there are no references in the literature about the use of the SMC 
in abc frame applied to control the grid-side current. Besides, with a direct control of the grid-side current high robustness against a distorted grid is achieved, and as a consequence, a reduction of the total harmonic distortion (THD) of the currents injected to the grid. Then, with this method, digital filters in the closed loop system are not required.

This paper proposes a sliding-mode controller based on a KF in order to perform a direct control of the current injected to the grid by imposing a desired dynamics. The proposed controller scheme estimates the state-space variables including the voltages at the point of common coupling (PCC). The SMC parameters are obtained by analyzing the system stability taking into account the influence of the KF. The estimated PCC voltages are used in a hysteresis current control (HCC) reducing the switching noise and improving the switching spectrum. The main advantage of this method is that it is not necessary to compensate the grid harmonics in order to achieve sinusoidal grid currents with a low THD [19]. Besides, since the control method is based on controlling the grid-side current instead of the inverterside current some problems are avoided such as: 1) the sensitivity to parameter uncertainties specifically with the grid inductance variations, and 2) the phase-shift between the current injected to the grid and its reference, which is more important for low values of active power.

Another interesting property is that the averaged neutral point voltage can be changed by modifying the space-state model of the converter used in the KF algorithm. As an example a third harmonic voltage can be injected in the neutral point in order to increase the control dynamic range. This property is useful in PV applications.

A methodology to analyze and design a robust controller of the grid current in natural reference frame is presented. This method is based on following steps:

1) A modified state-space model of the VSI is proposed to design three independent current controllers in natural reference frame.

2) The switching surfaces are designed in order to obtain a closed loop dynamics independent of the system parameters, using estimated variables obtained from a KF.

3) A complete stability analysis is performed taking into account the effect of the KF, the system discretization and the deviation in the system parameters. This analysis proves the system robustness.

4) Finally, experimental results are reported to prove the aforementioned properties, including the controller response against a distorted grid and voltage sags.
The paper is organized as follows. In Section II a linear model of the VSI with LCL filter is presented. Section III introduces the conventional SMC using the inverter-side current. Section IV presents the proposed control system. A stability analysis is presented in section VI. Experimental results are reported in section VI. Finally, section VII concludes the paper.

\section{Modeling OF VSI WITH LCL FILTER}

A circuit scheme of a grid-connected inverter with LCL filter is depicted in Fig.1. The three-phase system equations can be written as follows:

$$
\begin{aligned}
& L_{1} \frac{d \mathbf{i}_{1}}{d t}=\frac{V_{d c}}{2} \mathbf{u}-\mathbf{v}_{c}-v_{n} \mathbf{I}_{1} \\
& C \frac{d \mathbf{v}_{c}}{d t}=\mathbf{i}_{1}-\mathbf{i}_{2} \\
& L_{2} \frac{d \mathbf{i}_{2}}{d t}=\mathbf{v}_{c}-\mathbf{v}+\left(v_{n}-v_{n}^{\prime}\right) \mathbf{I}_{1}
\end{aligned}
$$

where $\mathbf{i}_{1}=\left[\begin{array}{lll}i_{1 a} & i_{1 b} & i_{1 c}\end{array}\right]^{T}$ are the inverter-side currents, $\mathbf{i}_{2}=\left[\begin{array}{lll}i_{2 a} & i_{2 b} & i_{2 c}\end{array}\right]^{T}$ are the grid-side currents, $\mathbf{v}_{c}=\left[\begin{array}{lll}v_{c a} & v_{c b} & v_{c c}\end{array}\right]^{T}$ are the capacitor voltages, $\mathbf{v}=\left[\begin{array}{lll}v_{a} & v_{b} & v_{c}\end{array}\right]^{T}$ are the voltages at the PCC, $\mathbf{u}=\left[\begin{array}{lll}u_{a} & u_{b} & u_{c}\end{array}\right]^{T}$ are the control variables, $v_{n}$ and $v_{n}^{\prime}$ are the voltages at the neutral points and $\mathbf{I}_{1}$ is a column vector defined as $\left[\begin{array}{lll}1 & 1 & 1\end{array}\right]^{T}$.

Assuming that the grid voltages are balanced (i.e., $v_{g a}+v_{g b}+v_{g c}=0$ and $v_{c a}+v_{c b}+v_{c c}=0$ ), the expressions for the neutral point voltages can be reduced as follows:

$$
v_{n}=v_{n}^{\prime}=\frac{V_{d c}}{6}\left(u_{a}+u_{b}+u_{c}\right) .
$$

The equations for the VSI model can be rewritten as a discrete space-state model. The discrete equations will be used in the stability analysis section in order to find the control parameters. The process and measurement discrete equations for each phase-leg $i$ are expressed as follows:

$$
\begin{gathered}
\mathbf{x}_{i}(k+1)=\mathbf{A} \mathbf{x}_{i}(k)+\mathbf{B} u_{i}(k)+\mathbf{D} v_{i}(k)-\frac{T_{s}}{L_{1}} v_{n}(k) \\
y_{i}(k)=\mathbf{C} x_{i}(k)
\end{gathered}
$$

where

$$
\mathbf{x}_{i}(k)=\left[\begin{array}{lll}
i_{1 i}(k) & v_{c i}(k) & i_{2 i}(k)
\end{array}\right]^{T}
$$

is the state space vector. The remaining matrices are defined as:

$$
\mathbf{A}=\left(\begin{array}{ccc}
1 & -\frac{T_{s}}{L_{1}} & 0 \\
\frac{T_{s}}{C} & 1 & -\frac{T_{s}}{C} \\
0 & \frac{T_{s}}{L_{2}} & 1
\end{array}\right)
$$




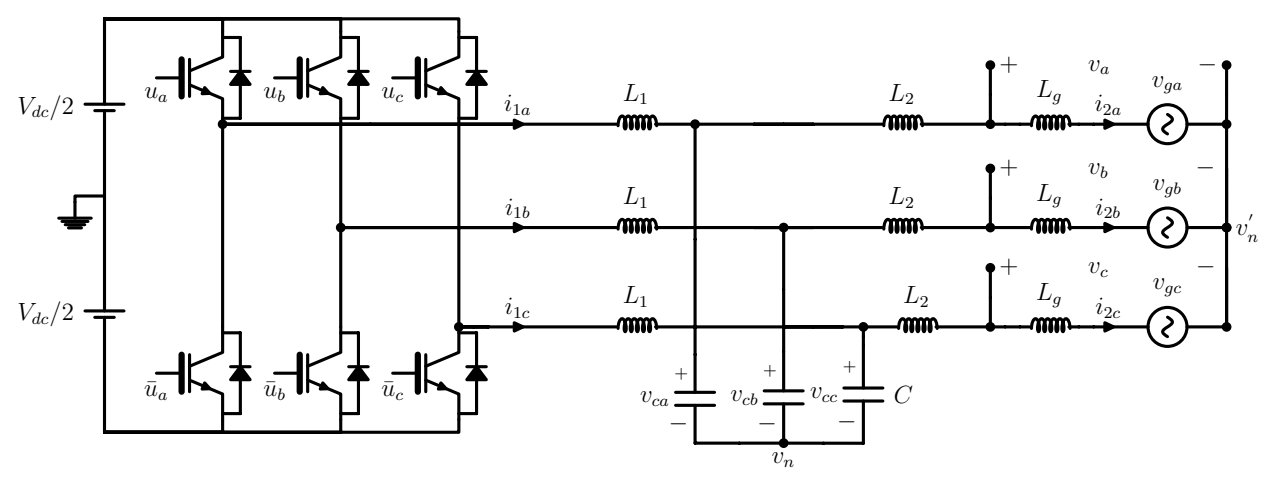

Fig. 1. Circuit diagram of three-phase grid-connedcted inverter with LCL-filter

$$
\begin{gathered}
\mathbf{B}=\left[\begin{array}{ccc}
\frac{V_{d c} T_{s}}{2 L_{1}} & 0 & 0
\end{array}\right]^{T} \\
\mathbf{C}=\left[\begin{array}{lll}
0 & 0 & 1
\end{array}\right] \\
\mathbf{D}=\left[\begin{array}{lll}
0 & 0 & -\frac{T_{s}}{L_{2}}
\end{array}\right]^{T}
\end{gathered}
$$

being $T_{s}$ the sampling time.

\section{Conventional SMC USing the INVERTER-SIDE CURRENT}

As a first approach, a sliding surface vector used to control the inverter-side currents can be defined as follows:

$$
\mathbf{S}=\mathbf{i}^{*}-\mathbf{i}_{1}
$$

where the reference current vector $\mathbf{i}^{*}=\left[\begin{array}{lll}i_{a}^{*} & i_{b}^{*} & i_{c}^{*}\end{array}\right]^{T}$ is given in [20], and defined as follows:

$$
\begin{aligned}
i_{a}^{*} & =\frac{P^{*}}{|\mathbf{v}|^{2}} v_{a}+\frac{Q^{*}}{\sqrt{3}|\mathbf{v}|^{2}}\left(v_{b}-v_{c}\right) \\
i_{b}^{*} & =\frac{P^{*}}{|\mathbf{v}|^{2}} v_{b}+\frac{Q^{*}}{\sqrt{3}|\mathbf{v}|^{2}}\left(v_{c}-v_{a}\right) \\
i_{c}^{*} & =-\left(i_{a}^{*}+i_{b}^{*}\right)
\end{aligned}
$$

being $|\mathbf{v}|^{2}=v_{a}^{2}+v_{b}^{2}+v_{c}^{2}=\frac{3 V_{p}^{2}}{2}$ with $V_{p}$ the peak voltage value, and $P^{*}$ and $Q^{*}$ the active and reactive power references, respectively.

When the system is in sliding regime, the converter dynamics is forced to evolve over the sliding surface, and the new dynamics can be derived according to the invariance conditions, $\mathbf{S}=0$ and $\dot{\mathbf{S}}=0$ [21]. By applying these conditions to (1)-(3), the following gridside current differential equation can be found:

$$
L_{2} C \frac{d^{2} \mathbf{i}_{2}}{d t^{2}}+\mathbf{i}_{2}=\mathbf{i}^{*}-C \frac{d \mathbf{v}}{d t} .
$$

The output current dynamics exhibits an oscillatory behavior, as it can be deduced from (16) where the resonance frequency is given by $1 / 2 \pi \sqrt{L_{2} C}$. The straightforward solution is to apply passive damping by connecting a resistor in series with the capacitor filter $C$. Then, the ideal sliding-mode dynamics results in:

$$
\begin{aligned}
\mathbf{i}_{1} & =\mathbf{i}^{*} \\
C \frac{d \mathbf{v}_{c}}{d t} & =\mathbf{i}^{*}-\mathbf{i}_{2} \\
L_{2} \frac{d \mathbf{i}_{2}}{d t} & =\mathbf{v}_{c}-\mathbf{v}+R_{d}\left(\mathbf{i}^{*}-\mathbf{i}_{2}\right)
\end{aligned}
$$

where $R_{d}$ is the damping resistor. From the last equations, the closed-loop grid-side current differential equation can be derived as follows:

$$
L_{2} C \frac{d^{2} \mathbf{i}_{2}}{d t^{2}}+R_{d} C \frac{d \mathbf{i}_{2}}{d t}+\mathbf{i}_{2}=\mathbf{i}^{*}+R_{d} C \frac{d \mathbf{i}^{*}}{d t}-C \frac{d \mathbf{v}}{d t} .
$$

Assuming a grid-connected application, where only active power is delivered to the grid, the reactive power is not considered (i.e. $Q^{*}=0$ ). Then, by applying the Laplace transform to 20, and using (13)-(15) with $Q^{*}=0$, the transfer function between the grid-side current and its reference is found:

$$
\mathbf{i}_{2}(s)=\frac{1+\left(R_{d}-\frac{3 V_{p}^{2}}{2 P^{*}}\right) C s}{L_{2} C s^{2}+R_{d} C s+1} \mathbf{i}^{*}(s)=H(s) \mathbf{i}^{*}(s) .
$$

As it can be deduced from (21), a phase shift between $\mathbf{i}_{2}$ and $\mathbf{i}^{*}$ is produced. Note that this phase shift depends of the reference active power value, $P^{*}$.

\section{Proposed Control System}

The control scheme for phase-leg $i$ is depicted in Fig.2. The control block diagram consists of a KF, a reference neutral point voltage calculator, and the switching surface used together with a variable hysteresis band combined with a switching decision algorithm [20]. This combination allows to obtain an improved switching spectrum concentrated around the desired switching frequency.

Besides, in this section, a KF algorithm based on a modified space-state model is presented. Finally, in order to obtain the control parameters a complete stability analysis is performed including the KF effect. 


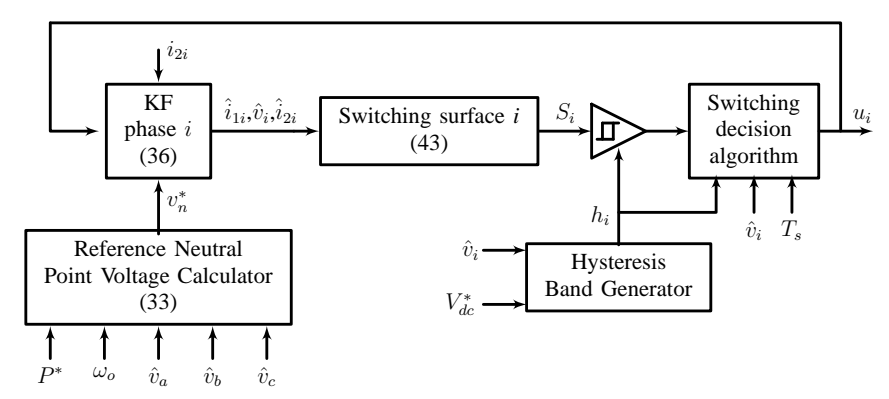

Fig. 2. Proposed control system for phase-leg $i$ of the VSI

\section{A. Kalman Filter}

1) Proposed Space-State model of the VSI: The proposed state-space model is defined by the following differential equations:

$$
\begin{aligned}
L_{1} \frac{d \mathbf{i}_{1}}{d t} & =\frac{V_{d c}}{2} \mathbf{u}-\mathbf{v}_{c}-v_{n}^{*} \mathbf{I}_{1} \\
C \frac{d \mathbf{v}_{c}}{d t} & =\mathbf{i}_{1}-\mathbf{i}_{2} \\
L_{2} \frac{d \mathbf{i}_{2}}{d t} & =\mathbf{v}_{c}-\mathbf{v} \\
\frac{d \mathbf{v}}{d t} & =\omega_{o} \mathbf{v}_{q} \\
\frac{d \mathbf{v}_{q}}{d t} & =-\omega_{o} \mathbf{v}
\end{aligned}
$$

where $v_{n}^{*}$ is the reference neutral point voltage, $\omega_{o}$ is the angular grid frequency and $\mathbf{v}$ and $\mathbf{v}_{q}$ are the voltages vector at the PCC and its quadrature, respectively. Note that, using $v_{n}^{*}$ in (22) instead of $v_{n}$ as in (1), a perfect decoupling between phases is obtained in the proposed model. This simple change allows the dynamics of the inverter-side current of each phase relying only on its corresponding control input. This fact can be clearly observed by considering the expression of $v_{n}$ written in (4).

By using this model, the KF is also applied to extract the fundamental component and its quadrature of the PCC voltages. This fact allows to generate sinusoidal reference currents even in case of a highly distorted grid [22].

In order to use the aforementioned model in a KF, a discrete model is necessary. The augmented discrete space-state model including the PCC voltages is written as follows:

$$
\begin{aligned}
\hat{\mathbf{x}}_{a u g i}(k+1) & =\hat{\mathbf{A}}_{\text {aug }} \hat{\mathbf{x}}_{a u g i}(k)+\mathbf{B}_{\text {aug }} u_{i}(k) \\
& -\frac{T_{s}}{L_{1}} v_{n}^{*}(k)+\boldsymbol{\eta}_{i}(k) \\
y_{i}(k) & =\mathbf{C}_{\text {aug }} x_{\text {augi }}(k)+\mathbf{w}_{i}(k)
\end{aligned}
$$

where $\mathbf{w}_{i}(k)$ and $\boldsymbol{\eta}_{i}(k)$ are the process and the measurement noise vectors respectively, and

$$
\begin{aligned}
& \hat{\mathbf{x}}_{\text {augi }}=\left[\begin{array}{lllll}
\hat{i}_{1 i}(k) & \hat{v}_{c i}(k) & \hat{i}_{2 i}(k) & \hat{v}_{i}(k) & \hat{v}_{i q}(k)
\end{array}\right]^{T} \\
& \mathbf{A}_{\text {aug }}=\left(\begin{array}{ccccc}
1 & -\frac{T_{s}}{L_{1}} & 0 & 0 & 0 \\
\frac{T_{s}}{C} & 1 & -\frac{T_{s}}{C} & 0 & 0 \\
0 & \frac{T_{s}}{L_{2}} & 1 & -\frac{T_{s}}{L_{2}} & 0 \\
0 & 0 & 0 & 1 & T_{s} \omega_{o} \\
0 & 0 & 0 & -T_{s} \omega_{o} & 1
\end{array}\right) \\
& \mathbf{B}_{a u g}=\left[\begin{array}{lllll}
\frac{V_{d c} T_{s}}{2 L_{1}} & 0 & 0 & 0 & 0
\end{array}\right]^{T} \\
& \mathbf{C}_{\text {aug }}=\left[\begin{array}{lllll}
0 & 0 & 1 & 0 & 0
\end{array}\right]^{T} .
\end{aligned}
$$

Note that the circumflex symbol denotes estimated variables.

We can take advantage of the reference neutral point voltage, $v_{n}^{*}$, shown in 22 to impose a desired voltage. For instance, a third harmonic can be imposed at the neutral point, which can be obtained following the steps in [20], and it is expressed as:

$$
\begin{aligned}
v_{n}^{*} & =\frac{V_{p}}{6}\left[\left(L_{1}+L_{2}\right) \frac{P^{*} \omega_{o}}{|\widehat{\mathbf{v}}|^{2}} \cos \left(3 \omega_{o} t\right)\right. \\
& \left.+\left(1+\left(L_{1}+L_{2}\right) \frac{Q^{*} \omega_{o}}{|\widehat{\mathbf{v}}|^{2}}\right) \sin \left(3 \omega_{o} t\right)\right] .
\end{aligned}
$$

where $|\hat{\mathbf{v}}|=\left[\begin{array}{lll}\hat{v}_{a} & \hat{v}_{b} & \hat{v}_{c}\end{array}\right]$ is the vector of estimated voltages at the PCC.

The last expression does not have any dependence with the control signals $u_{a, b, c}$. For this reason, this solution not only increases the controllers dynamic range, but also achieves a perfect decoupling between controllers.

On the other hand, the system is controlled using only one sensor in the grid-side current, as it is shown in Fig.2. Then, the system observability and controllability should be ensured. The observability matrix can be obtained from (30) and (32) which yields to

$$
\begin{aligned}
\mathbf{O}= & {\left[\begin{array}{llll}
\mathbf{C}_{\text {aug }} & \mathbf{C}_{\text {aug }} \mathbf{A}_{\text {aug }} & \mathbf{C}_{\text {aug }} \mathbf{A}_{\text {aug }}^{2} & \mathbf{C}_{\text {aug }} \mathbf{A}_{\text {aug }}^{3} \\
& \mathbf{C}_{\text {aug }} \mathbf{A}_{\text {aug }}^{4}
\end{array}\right]^{T} }
\end{aligned}
$$

and using (30) and (31) the controllability matrix $\boldsymbol{\Gamma}$ is given by

$$
\begin{aligned}
\boldsymbol{\Gamma}= & {\left[\begin{array}{llll}
\mathbf{B}_{\text {aug }} & \mathbf{A}_{\text {aug }} \mathbf{B}_{\text {aug }} & \mathbf{A}_{\text {aug }}^{2} \mathbf{B}_{\text {aug }} & \mathbf{A}_{\text {aug }}^{3} \mathbf{B}_{\text {aug }} \\
& \mathbf{A}_{\text {aug }}^{4} \mathbf{B}_{\text {aug }}
\end{array}\right] }
\end{aligned}
$$

Matrix $\mathbf{O}$ is of full-rank, (i.e. $\operatorname{rank}\{\mathbf{O}\}=5$ ), and as a consequence the system is observable using only the measured current $i_{2 i}$. However, the controllability matrix is of rank 3 and only a controllable subspace can be considered. Note that in this particular case the controllable subspace is given by matrix (8) which contains the control variable $i_{2 i}$. Besides, the states $v_{i}$ and $v_{i q}$ are stable states with bounded limits, therefore the controllability is ensured. 
2) KF Algorithm: The KF algorithm is widely explained in the literature [23] so only a brief summary of its equations will be given in this section. The recursive Kalman algorithm computation is divided in two parts: 1) time updating and 2) measurement updating. From the well-known equations of the KF [24], the equation for the estate estimation can be expressed as follows:

$$
\widehat{\mathbf{x}}_{\text {augi }}(k+1)=\widehat{\mathbf{x}}_{\text {augi }}(k)+\mathbf{L}_{i}(k)\left(i_{2 i}(k)-\widehat{i}_{2 i}(k)\right)
$$

where the Kalman gain is computed as:

$$
\mathbf{L}_{i}(k)=\mathbf{P}_{i}(k) \mathbf{C}^{T}\left(\mathbf{C P}_{i}(k) \mathbf{H}^{T}+\mathbf{R}_{i}(k)\right)^{-1}
$$

being $\mathbf{P}_{i}$ the error covariance matrix for phase-leg $i$ and $R_{i}$ the measurement noise covariance matrix. The algorithm and some interesting steps to reduce the computational time are explained in [24].

\section{B. Derivation of the SMC by dynamic imposition}

In this paper, the sliding surfaces are designed by imposing a desired dynamics behaviour with active damping capability. The sliding surfaces will be used as grid-current controllers in order to achieve high current tracking accuracy with stable dynamics. In the switching surfaces implementation only estimated variables are used.

The first step in a switching surface design is to calculate the relative degree associated with the output variable. The desired closed-loop output-current dynamics can be then specified according to the relative degree of $\hat{\mathbf{i}}_{2}$. The relative degree of a state variable is the smallest number of differentiations with regards to time, so that the control input $u$ appears explicity [21]. From (22)-(24) it can be easily found that

$$
\begin{array}{ll}
\frac{\partial}{\partial u}\left(\frac{d^{j} \hat{\mathbf{i}}_{2}}{d t^{j}}\right)=0 & j=1,2 \\
\frac{\partial}{\partial u}\left(\frac{d^{j} \hat{\mathbf{i}}_{2}}{d t^{j}}\right) \neq 0 \quad j=3
\end{array}
$$

then, the relative degree of $\hat{\mathbf{i}}_{2}$ is three. From (1)-(3) the open-loop output-current dynamics can be expressed as follows:

$$
L_{2} C \frac{d^{3} \hat{\mathbf{i}}_{2}}{d t^{3}}+\frac{d \hat{\mathbf{i}}_{2}}{d t}-\frac{d \hat{\mathbf{i}}_{1}}{d t}+C \frac{d^{2} \hat{\mathbf{v}}}{d t^{2}}=0 .
$$

Note that in the previous expression, the control action $\mathbf{u}$ is in the time derivative term of $\widehat{\mathbf{i}}_{1}$.

The choice of the sliding surface vector $\mathbf{S}$ constitutes the second step. Here, we introduce the use of invariance conditions to synthesize proper sliding surfaces to guarantee perfect tracking dynamics, $\mathbf{i}_{2}=\mathbf{i}^{*}$.
The desired closed-loop linear dynamics which guarantees a perfect tracking performance until the third derivative term of the output-current error is

$$
\sum_{n=0}^{3} \lambda_{n} \frac{d^{n}\left(\hat{\mathbf{i}}_{2}-\mathbf{i}^{*}\right)}{d t^{n}}=0 .
$$

It is worth to mention that, this ideal dynamics does not rely on the system parameters, and only depends of the controller parameters, $\lambda$. This fact provides a hight robustness against system parameters deviations. However, since a KF is used, the effect of the KF and the system discretization should be analyzed. For this reason, in section $\mathrm{V}$, a complete analysis of system stability and robustness against system parameters deviation will be performed.

Here, it is important to remark that the order of the specified dynamics coincides with the relative degree of the output-current; otherwise, the desired dynamics cannot be ensured by the control action $u$ [25], [26].

In sliding regime, the converter dynamics are forced to evolve over the sliding surface $\mathbf{S}$, according to the invariance condition $\mathbf{S}=\dot{\mathbf{S}}=0$ [25]. Such property can be used to design a controller that guarantees the desired dynamics (41). In fact, a similar approach was previously employed in [27] in a different application, with good static and dynamic properties.

Now, by subtracting (40) from (41) and equalizing the result to the invariance condition $\dot{\mathbf{S}}=0$ [25] yields

$$
\begin{aligned}
\frac{d \mathbf{S}}{d t} & =\frac{d \hat{\mathbf{i}}_{1}}{d t}-\frac{d \hat{\mathbf{i}}_{2}}{d t}-C \frac{d^{2} \hat{\mathbf{v}}}{d t^{2}}-L_{2} C \frac{d^{3} \hat{\mathbf{i}}_{2}}{d t^{3}} \\
& +\sum_{n=0}^{3} \lambda_{n} \frac{d^{n}\left(\hat{\mathbf{i}}_{2}-\mathbf{i}^{*}\right)}{d t^{n}}
\end{aligned}
$$

and consequently

$$
\begin{aligned}
\mathbf{S} & =\hat{\mathbf{i}}_{1}-\hat{\mathbf{i}}_{2}-C \frac{d \hat{\mathbf{v}}}{d t}-L_{2} C \frac{d^{2} \hat{\mathbf{i}}_{2}}{d t^{2}}+\sum_{n=1}^{3} \lambda_{n} \frac{d^{n-1}\left(\hat{\mathbf{i}}_{2}-\mathbf{i}^{*}\right)}{d t^{n-1}} \\
& +\lambda_{0} \int\left(\hat{\mathbf{i}}_{2}-\mathbf{i}^{*}\right) d t .
\end{aligned}
$$

The aforementioned expression can be simplified by taking $\lambda_{3}=L_{2} C$ and considering that $\lambda_{3} \frac{d^{2} i^{*}}{d t^{2}}<<\lambda_{1} i^{*}$, as:

$$
\begin{aligned}
\mathbf{S} & =\hat{\mathbf{i}}_{1}-\hat{\mathbf{i}}_{2}-C \frac{d \hat{\mathbf{v}}}{d t}+\lambda_{2} \frac{d\left(\hat{\mathbf{i}}_{2}-\mathbf{i}^{*}\right)}{d t}+\lambda_{1}\left(\hat{\mathbf{i}}_{2}-\mathbf{i}^{*}\right) \\
& +\lambda_{0} \int\left(\hat{\mathbf{i}}_{2}-\mathbf{i}^{*}\right) d t .
\end{aligned}
$$

The last requirement in the design of SMC is to satisfy the reaching conditions. The most often-used reaching conditions for each phase-leg $i$ are given by

$$
S_{i} \dot{S}_{i}<0
$$


which allows us to determine the control law

$$
u_{i}=\left\{\begin{array}{lll}
1 & \text { if } & S_{i}<0 \\
-1 & \text { if } & S_{i}>0
\end{array}\right.
$$

In section $\mathrm{V}$, an analysis of the closed-loop system stability is performed in order to obtain the control parameters.

\section{Stability Analysis}

In this section the stability of the proposed control system is analyzed. This analysis takes into account the effect of the KF because it modifies the system dynamics behaviour. According to section IV-A, the controllers are decoupled, and each phase-leg can be treated independently in order to perform the stability analysis.

\section{A. Discrete equivalent control deduction}

For this analysis, only the state variables $i_{1 i}, v_{c i}$ and $i_{2 i}$ are used, and the voltages at the PCC are considered as disturbances. In this case the state-space system equations for each phase-leg $i$ can be defined as follows:

$$
\begin{aligned}
\mathbf{x}_{i}(k+1) & =\mathbf{A} \mathbf{x}_{i}(k)+\mathbf{B} u(k)+\mathbf{f}(k) \\
y_{i}(k) & =\mathbf{C} \mathbf{x}_{i}(k)
\end{aligned}
$$

where matrix $\mathbf{A}$, and vectors $\mathbf{B}$ and $\mathbf{C}$ are defined in $(8),(9)$ and (10) respectively, and $\mathbf{f}(k)$ is a disturbance vector.

The discrete sliding surface equation can be obtained from (43) yielding:

$$
\begin{aligned}
S_{i}(k) & =\hat{i}_{1 i}(k)-\hat{i}_{2 i}(k)+\lambda_{2} \frac{\hat{i}_{2 i}(k)-\hat{i}_{2 i}(k-1)}{T_{s}} \\
& +\lambda_{1} \hat{i}_{2 i}(k)+\lambda_{0} \xi_{i}(k)+g\left(\hat{v}, i_{i}^{*}\right) .
\end{aligned}
$$

where the integral term is defined as

$$
\xi_{i}(k)=\xi_{i}(k-1)+T_{s} \mathbf{C x}_{i}(k)
$$

and $g\left(\hat{v}, i_{i}^{*}\right)$ is a function with bounded limits depending of the disturbances. The last expression can be rewritten as follows:

$$
S_{i}(k)=\mathbf{a} \hat{\mathbf{x}}_{i}(k)+\mathbf{b} \hat{\mathbf{x}}_{i}(k-1)+\lambda_{0} \xi_{i}(k)+g\left(\hat{v}, i_{i}^{*}\right) .
$$

where

$$
\begin{aligned}
\mathbf{a} & =\left[\mathbf{H}+\mathbf{C}\left(\frac{\lambda_{2}}{T_{s}}+\lambda_{1}-1\right)\right] \\
\mathbf{b} & =-\frac{\lambda_{2}}{T_{s}} \mathbf{C} \\
\mathbf{H} & =\left[\begin{array}{lll}
1 & 0 & 0
\end{array}\right] .
\end{aligned}
$$

and

$$
\hat{\mathbf{x}}_{i}=\left[\begin{array}{lll}
\hat{i}_{1 i} & \hat{v}_{c i} & \hat{i}_{2 i}
\end{array}\right]^{T} .
$$

Vector $\hat{x}_{i}(k+1)$ is the estimated state vector which can be obtained using the KF estimation as

$$
\hat{\mathbf{x}}_{i}(k+1)=\hat{\mathbf{A}} \hat{\mathbf{x}}_{i}(k)+\mathbf{B} \hat{u}_{i e q}+\mathbf{L}_{i} \mathbf{C e}(k)
$$

where $\hat{\mathbf{A}}$ is the system matrix obtained from the proposed model which contains the $L C L$ nominal values, $\mathbf{A}$ is the real system matrix defined in $(8), \mathbf{e}_{i}(k)=$ $\mathbf{x}_{i}(k)-\hat{\mathbf{x}}_{i}(k)$ is the estimation error and $u_{i e q}(k)$ is the equivalent control of phase-leg $i$, which is the solution of $\Delta S_{i}=S_{i}(k+1)-S_{i}(k)=0$, [28].

Taking into account the aforementioned expression, the discrete equivalent control can be found by using (56) in (51) evaluated at time $k+1$, yielding

$$
\begin{aligned}
\hat{u}_{i e q}(k) & =-(\mathbf{G B})^{-1}\left(S_{i}(k)+\mathbf{a}(\mathbf{G} \hat{\mathbf{A}}+\mathbf{b}) \hat{\mathbf{x}}_{i}(k)\right. \\
& \left.+\mathbf{G L}_{i} \mathbf{C e}(k)+\lambda_{o} \xi_{i}(k)+g\left(\hat{v}, i_{i}^{*}\right)\right)
\end{aligned}
$$

where the gain matrix $\mathbf{G}$ is expressed as:

$$
\mathbf{G}=\mathbf{a}+\lambda_{0} T_{s} \mathbf{C} .
$$

\section{B. Closed-loop equations}

In the ideal sliding regime, one has $S_{i}(k+1)=$ $S_{i}(k)=0$. Then, (57) can be reduced to:

$$
\hat{u}_{i e q}(k)=\mathbf{K}_{1} \hat{\mathbf{x}}_{i}(k)+\mathbf{K}_{2} \mathbf{e}(k)+\mathbf{K}_{3} \xi_{i}(k)
$$

where the gains $\mathbf{K}_{1}, \mathbf{K}_{2}$ and $\mathbf{K}_{3}$ are defined as follows:

$$
\begin{aligned}
& \mathbf{K}_{1}=-(\mathbf{G B})^{-1}(\mathbf{G} \hat{\mathbf{A}}+\mathbf{b}) \\
& \mathbf{K}_{2}=-(\mathbf{G B})^{-1} \mathbf{G L}_{i} \mathbf{C} \\
& \mathbf{K}_{3}=-(\mathbf{G B})^{-1} \lambda_{0} .
\end{aligned}
$$

Note that the disturbances function $g\left(\hat{v}, i_{i}^{*}\right)$ has been removed for simplicity, since it has no effect in the stability analysis.

In order to find the closed-loop equations, (59) is replaced in (47) and in (56). Assuming $f(k)$ in (47) has bounded limits, these function can also be removed for the stability analysis procedure, leading to

$$
\begin{aligned}
\mathbf{x}_{i}(k+1) & =\left(\mathbf{A}+\mathbf{B} \mathbf{K}_{1}\right) \mathbf{x}_{i}(k)+\mathbf{B}\left(\mathbf{K}_{2}-\mathbf{K}_{1}\right) \mathbf{e}_{i}(k) \\
& +\mathbf{B} \mathbf{K}_{3} \xi_{i}(k)
\end{aligned}
$$

$$
\begin{aligned}
\hat{\mathbf{x}}_{i}(k+1) & =\left(\hat{\mathbf{A}}+\mathbf{B} \mathbf{K}_{1}\right) \mathbf{x}_{i}(k)+\left(\mathbf{B}\left(\mathbf{K}_{2}-\mathbf{K}_{1}\right)+\mathbf{L}_{i} \mathbf{C}\right. \\
& -\hat{\mathbf{A}}) \mathbf{e}_{i}(k)+\mathbf{B} \mathbf{K}_{3} \xi_{i}(k) .
\end{aligned}
$$


Now, by subtracting (64) from (63), the equation for the estimation error at time $k+1$ is obtained

$$
\mathbf{e}(k+1)=(\mathbf{A}-\hat{\mathbf{A}}) \mathbf{x}_{i}(k)+\left(\hat{\mathbf{A}}-\mathbf{L}_{i} \mathbf{C}\right) \mathbf{e}(k)
$$

The closed-loop equations are defined by (63) and (65). Then by taking into account that

$$
\xi_{i}(k+1)=\xi_{i}(k)+T_{s} \mathbf{C} \hat{\mathbf{x}}_{i}(k+1)
$$

and using (56) in (66), the closed-loop equations in matrix form can be found:

$$
\left(\begin{array}{c}
\mathbf{x}_{i}(k+1) \\
\mathbf{e}_{i}(k+1) \\
\xi_{i}(k+1)
\end{array}\right)=\mathbf{G}\left(\begin{array}{c}
\mathbf{x}_{i}(k) \\
\mathbf{e}_{i}(k) \\
\xi_{i}(k)
\end{array}\right)
$$

where matrix $\mathbf{G}$ can defined as follows

$$
\mathbf{G}=\left(\begin{array}{ccc}
\mathbf{A}+\mathbf{B K}_{1} & \mathbf{B}\left(\mathbf{K}_{2}-\mathbf{K}_{1}\right) & \mathbf{B K}_{3} \\
(\mathbf{A}-\hat{\mathbf{A}}) & \hat{\mathbf{A}}-\mathbf{L}_{i} \mathbf{C} & \mathbf{0} \\
T_{s} \mathbf{C}\left(\mathbf{A}+\mathbf{B} \mathbf{K}_{1}\right) & \mathbf{J} & T_{s} \mathbf{B} \mathbf{K}_{3}+1
\end{array}\right)
$$

being

$$
\mathbf{J}=T_{s} \mathbf{C B}\left(\left(\mathbf{K}_{2}-\mathbf{K}_{1}\right)-\hat{\mathbf{A}}+\mathbf{L}_{i} \mathbf{C}\right)
$$

\section{Closed-loop poles}

The closed-loop dynamic behaviour will be given by the eigenvalues of matrix $\mathbf{G}$, which are the solution of $\operatorname{det}(z \mathbf{I}-\mathbf{G})=0$. In order to ensure the system stability, the eigenvalues should lie inside the unity circle in the $z$-plane. In a first stage, we assume that the system parameters deviations are zero. In this case it is accomplished that $\mathbf{A}=\hat{\mathbf{A}}$ in the matrix $\mathbf{G}$.

The converter open-loop poles in each phase-leg $i$ are three (5), but the observer introduces three more poles (56). When the system is in closed-loop operation, one more pole is added due to the presence of the integrator in the sliding surface, being seven the total number of poles.

However, it is found that while the system is in slidingregime, one pole is fixed at the origin $(z=0)$ due to the sliding equation, which forces the grid-side current to track its reference (i.e. $\mathbf{i}_{2}=\mathbf{i}^{*}$ ), and as a consequence, the system order is reduced in one unit. The position of the remaining poles can be adjusted by tuning the control parameters.

The pole maps for two different cases are presented in Fig.3. As it can be seen, the three poles provided by the KF lie in the same position in both figures since the Kalman gain is fixed. The position of the other three poles can be adjusted by changing $\lambda$ parameters. In Fig.3(a) the control parameters are selected for an oscillating behaviour and these poles are outside the unity

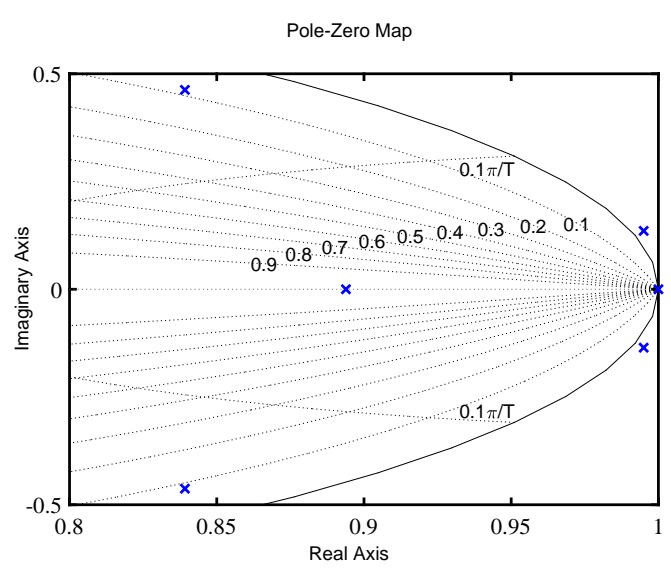

(a)

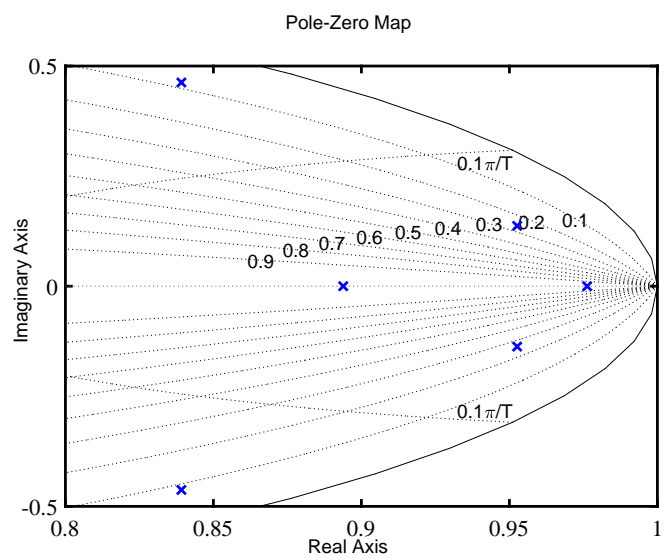

(b)

Fig. 3. System poles (a) in an oscillation case $\left(\lambda_{3}=34 \cdot 10^{-9}\right.$, $\lambda_{2}=\lambda_{0}=0$ and $\left.\lambda_{1}=1\right)$, (b) used in the proposed controller $\left(\lambda_{3}=34\right.$. $10^{-9}, \lambda_{2}=136 \cdot 10^{-6}, \lambda_{1}=1.136$ and $\lambda_{0}=1000$.

circle in the complex $z$ plane. In Fig.3(b) the control parameters are changed, and the poles are attracted inside the unity circle providing stable dynamics.

\section{System parameters robustness analysis}

In the previous section the stability of the system has been analyzed. However, the deviations of the LCL filter parameters should be studied. Here, we assume that $\mathbf{A} \neq$ $\hat{\mathbf{A}}$, which means that the reactive components do not coincide with their nominal values. Note that according to the matrix $\mathbf{G}$, the overall system stability does not rely on the grid inductance variations. This is an important feature of the proposed control algorithm that will be shown in the experimental results section.

Figs.4(b)-4(c) show the roots locus of the closed loop system in the case of parameter deviations in the $L C L$ filter. According to [29], deviations of $\pm 30 \%$ on the rated values have been taken to verify the system 
TABLE I

SYSTEM PARAMETERS

\begin{tabular}{ccc}
\hline \hline Symbol & Description & Value \\
\hline$L_{1}$ & Filter input inductance & $7 \mathrm{mH}$ \\
$C$ & Filter Capacitor & $6.8 \mathrm{uF}$ \\
$L_{2}$ & Filter output inductance & $5 \mathrm{mH}$ \\
$L_{g}$ & Grid inductance & $0.8 \mathrm{mH}-5 \mathrm{mH}$ \\
$V_{d c}$ & DC-link Voltage & $450 \mathrm{~V}$ \\
$f_{s}$ & Sampling frequency & $40 \mathrm{kHz}$ \\
$f_{\text {grid }}$ & Grid frequency & $60 \mathrm{~Hz}$ \\
$f_{s w}$ & Switching frequency & $6 \mathrm{kHz}$ \\
$V_{\text {grid }}$ & Grid Voltage & $110 \mathrm{~V}$ \\
$P^{*}$ & Active Power & $1.5 \mathrm{~kW}$ \\
$Q^{*}$ & Reactive Power & $0 \mathrm{VAr}$ \\
\hline
\end{tabular}

robustness. In each case, variations of only one parameter in the system matrix $\mathbf{A}$ are applied, while the rest of the parameters remains unchanged. It must be noticed that, for this analysis the matrix $\hat{\mathbf{A}}$ should contain the LCL nominal values. From the figures, it can be seen that the eigenvalues have small variation for a large variations of the LCL parameters. This fact verifies the high robustness of the proposed control method against deviations in the system parameters. In order to conclude the robustness analysis, different tests with harmonics in the grid and voltage sags will be shown in the experimental results section.

\section{EXPERIMENTAL VALIDATION}

An experimental three-phase three-wire inverter prototype was built using a 4.5-kVA SEMIKRON full-bridge as the power converter and a TMS320F28M35 floatingpoint digital signal processor (DSP) as the control platform with a sampling frequency of $40 \mathrm{kHz}$. The grid and the DC-Link voltages have been generated using a PACIFIC 360-AMX and an AMREL SPS1000-10-K0E3 sources respectively. A photograph of the experimental setup is shown in Fig.5. Table I lists the system parameters used in the experimental prototype. Some results are imported to Matlab by means of a script which communicates the computer with the DSP.

Fig.6 shows the equivalent control for phase-leg $a$, obtained by low-pass filtering the control signal $u_{a}$. The equivalent control is affected by the reference neutral point voltage which injects a third harmonic in the control signal as desired. As a consequence, the dynamic control range is extended by simply including the suitable reference neutral point voltage in the KF algorithm.

Fig.7 compares the tracking performances of the proposed control method with the conventional SMC when only active power is injected to the grid. In Fig7(a) and Fig.7(b) conventional SMC expressed in (12) with a physical damping resistor of $68 \Omega$ is used. The damping

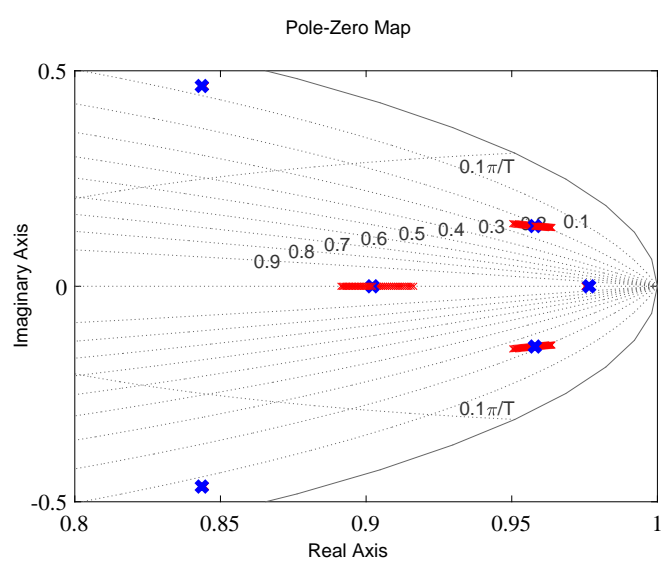

(a)

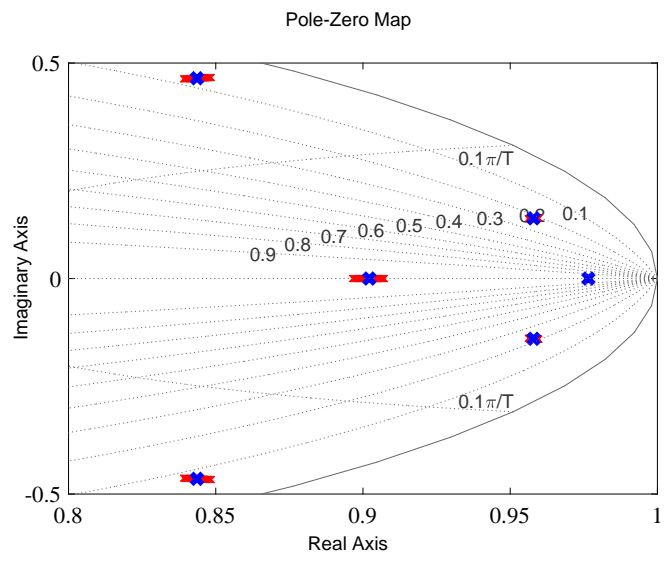

(b)

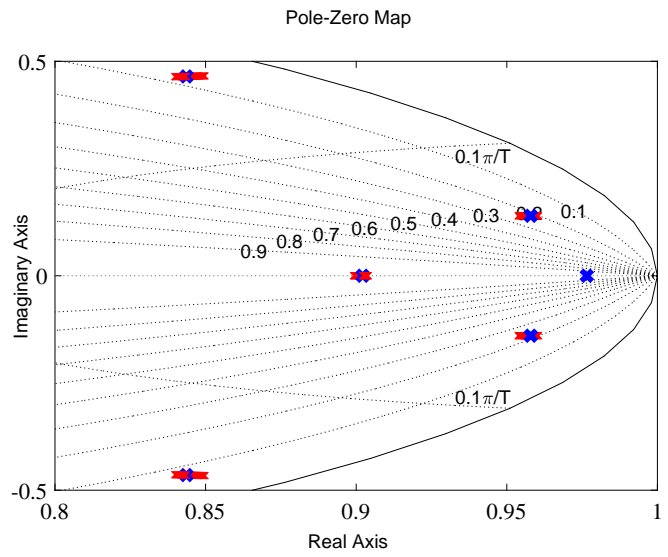

(c)

Fig. 4. Root locus diagrams when the filter parameters vary. a) $L_{1}$ varies $\pm 30 \%$, b) $L_{2}$ varies $\pm 30 \%$, and c) $\mathrm{C}$ varies $\pm 30 \%$. 


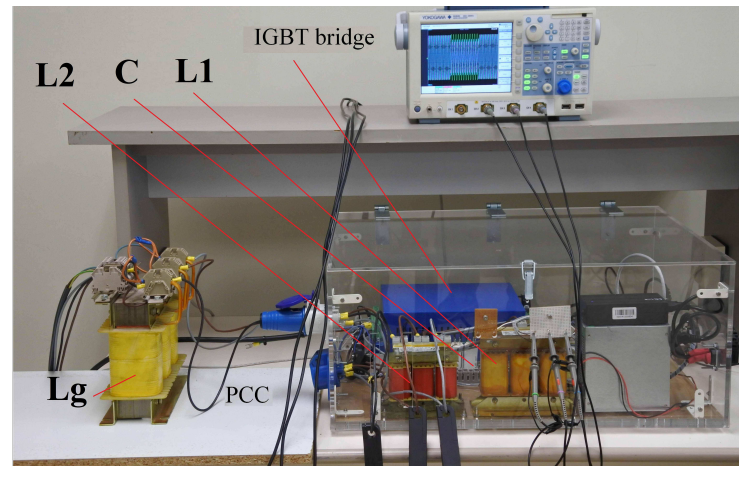

Fig. 5. Photograph of the experimental setup

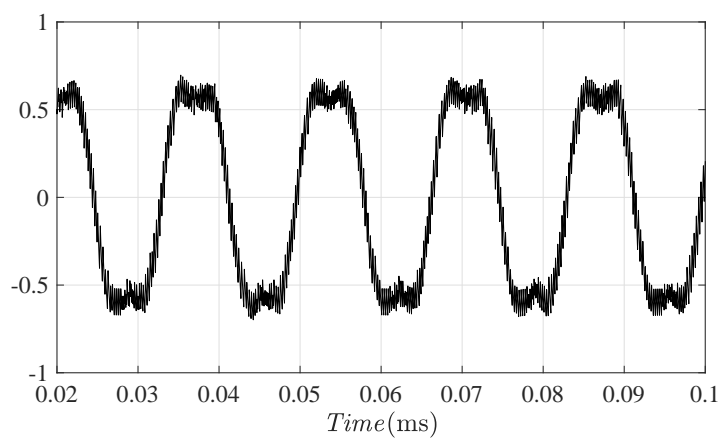

Fig. 6. Equivalent control with a common-mode third harmonic injected.

resistor is selected in accordance with guidelines reported [30]. Fig.7(a) shows a phase-shift around $7^{\circ}$ when the reference active power is $750 \mathrm{~W}$. This phase-shift is reduced when the reference active power is increased up to $1500 \mathrm{~W}$ as shows Fig.7(b). It can be seen from both figures that using the conventional SMC the phase shift has a dependence on the power injected to the grid according to (21).

If the proposed controller (43) is used the grid-side current tracks its reference without error regardless of $P^{*}$, as it is shown in Fig.7(c) and Fig.7(d).

\section{A. Test of the VSI against sudden changes in the active power reference}

Fig.8(a) and Fig.8(b) show the grid-side currents and the active and reactive power, respectively. Three cases are considered: oscillation behavior, stable behaviour and a power step change, as described as follows:

1) In the oscillation case, the control parameters $\lambda_{0}=\lambda_{2}=0$ and $\lambda_{1}=1$ are chosen and the system is oscillating, as predicted in Fig.3(a). In this case the SMC is used to control the inverter-side current as in section III (see eq.(12)).

2) In the stable case, the control parameters $\lambda_{0}$ and $\lambda_{2}$ are selected 1000 and $136 \cdot 10^{-6}$ respectively. In this case, grid currents and powers track their respective references.

3) Finally, in the case of an active power step change, from $750 \mathrm{~W}$ to $1500 \mathrm{~W}$, a stable operation with fast transient response is achieved due to the use of the SMC, as shown in Fig.8(b).

\section{B. Test of robustness against grid inductance variations}

Fig.9(a) shows the grid-side current of phase-leg $a$ for three different values of the grid inductance, $0.8 \mathrm{mH}$, $2 m H$ and $5 m H$, when the conventional SMC is used. An oscillatory behaviour in the grid-side currents appears when the grid inductance is more than $3 \mathrm{mH}$. When the proposed control is used this oscillation disappears, as it can be seen in Fig.9(b), which makes the system robust against grid inductance variations.

\section{Test of VSI under a distorted grid}

Fig.10 compares the three-phase grid currents using the conventional SMC (12) and using the proposed control method in the case of a distorted grid. This figure shows the distorted PCC voltages, which THD is around $16 \%$, and the grid-side currents. From the figure, when the conventional SMC is used, a distortion in the grid currents appears. The reason is that the method for generating the reference currents uses distorted PCC voltages. In contrast, when the proposed control method is used, the grid currents are sinusoidal since the reference current is generated by using only the fundamental component of the PCC voltage, which is obtained from the KF. Note that with this proposal, the use of extra filters for the grid voltages is not necessary.

\section{Test of the VSI under voltage SAGS}

The proposed controller can also operate in case of voltage sags. Fig. 11 shows the VSI performance under grid voltage sags. For this test, a voltage sag characterized by a positive and negative sequence of $V^{+}=0.7$ p.u. and $V^{-}=0.3$ p.u. respectively, and with a phase angle between sequences of $\phi=-\pi / 6$ has been provoked. The reference currents are obtained using the positive sequence of the PCC voltage, using $\hat{i}_{a, b, c}^{*}=\frac{P^{*}}{|\hat{\mathbf{v}}|^{2}} \hat{v}_{a, b, c}^{+}$. The positive sequence is computed from the estimated PCC voltages and their quadratures obtained from the $\mathrm{KF}$, following similar steps as shown in [31]. Note that the use of a specific PLL algorithm for extracting the 


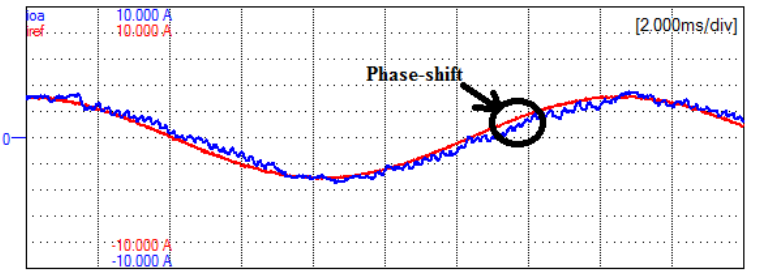

(a)

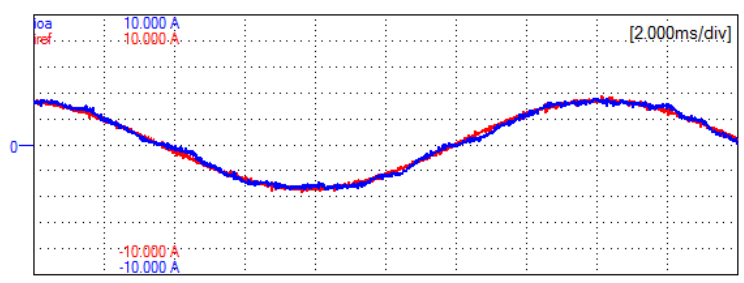

(c)

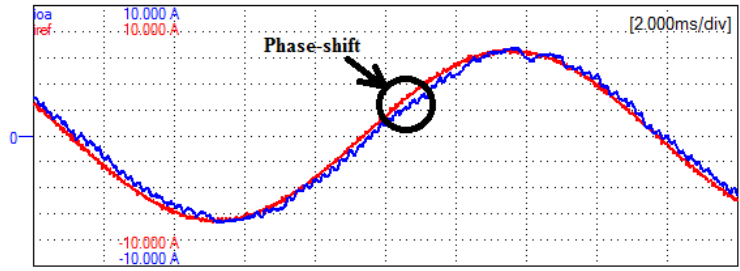

(b)

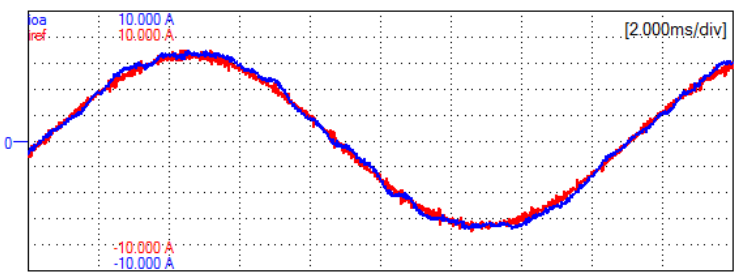

(d)

Fig. 7. Grid-side current (red line) tracking its reference (blue line) in phase-leg $a(2 \mathrm{~A} / \mathrm{div})$ using: a) conventional SMC with $P^{*}=750 \mathrm{~W}$, b) conventional SMC with $P^{*}=1500 \mathrm{~W}$, c) proposed controller with $P^{*}=750 \mathrm{~W}$, and d) proposed controller with $P^{*}=1500 \mathrm{~W}$.

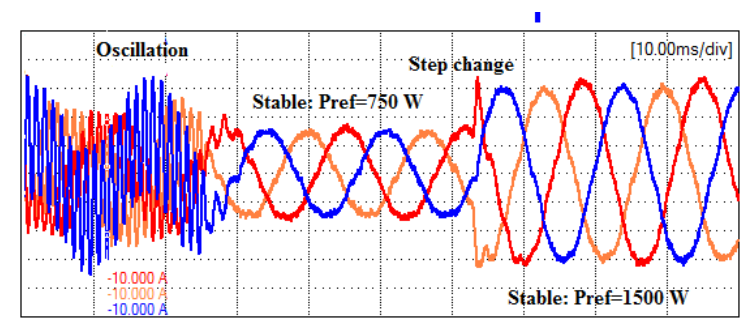

(a)

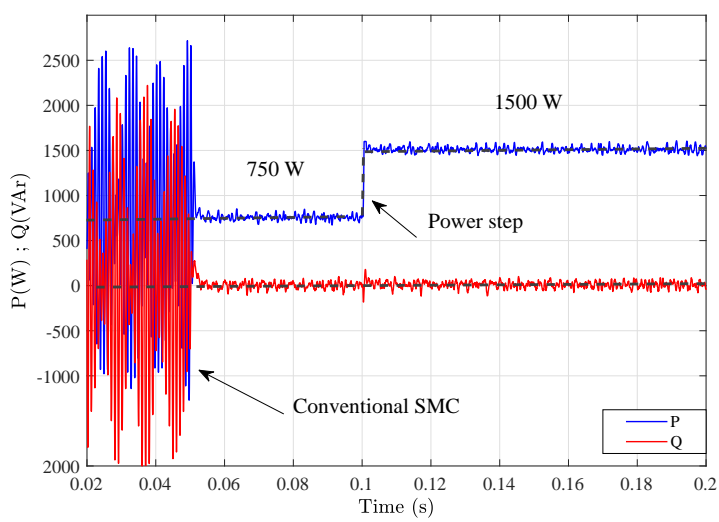

(b)

Fig. 8. a) Grid-side currents (2 A/div) and b) active and reactive power, in an oscillation case, stable case and with a sudden step change in the active power reference.

positive and negative sequence grid voltage components is not necessary in this case. Note that the currents amplitude is increased in order to maintain the desired active power due to the sag.

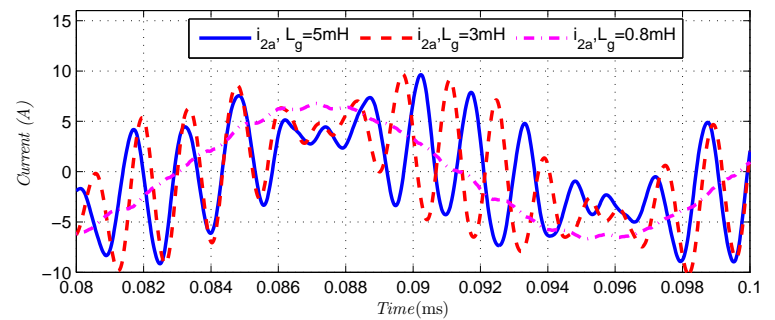

(a)

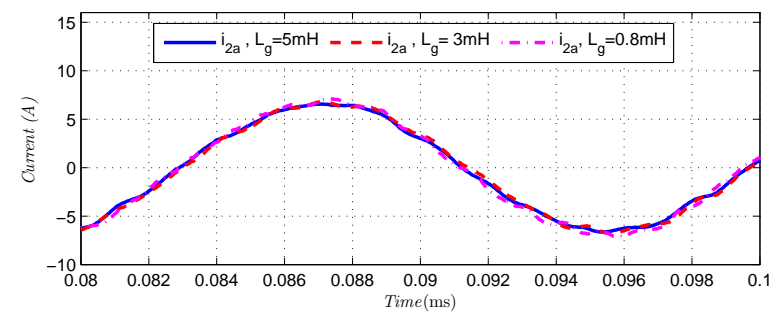

(b)

Fig. 9. Grid-side current of phase-leg $a$ for different grid inductance values (a) using conventional SMC, and (b) using the proposed controller.

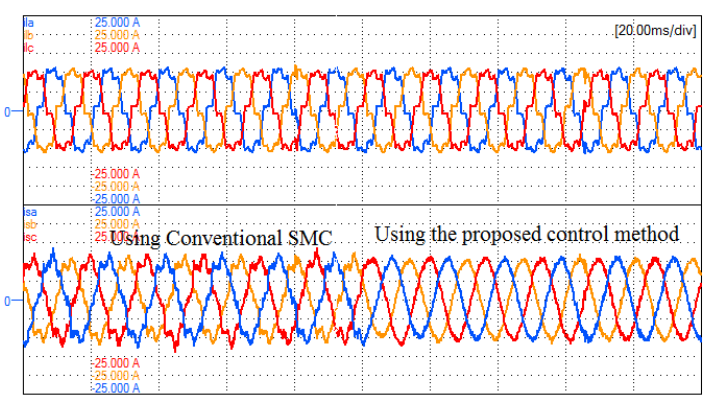

Fig. 10. Distorted PCC voltages (25V/div) with THD $=16 \%$, and grid-side currents $(5 \mathrm{~A} / \mathrm{div})$ 


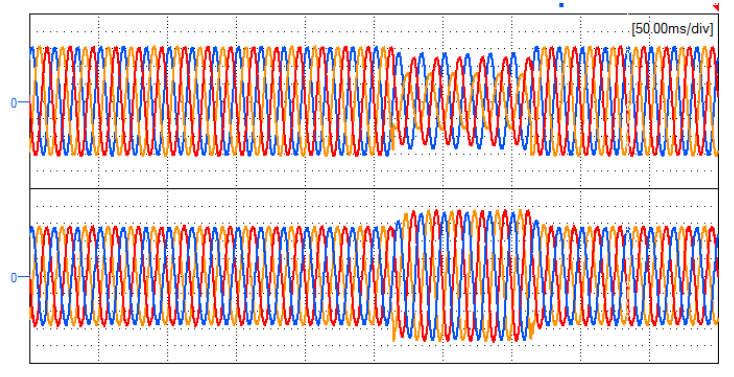

Fig. 11. PCC voltages $(50 \mathrm{~V} / \mathrm{div})$ and grid-side currents $(2 \mathrm{~A} / \mathrm{div})$ under voltage sag.

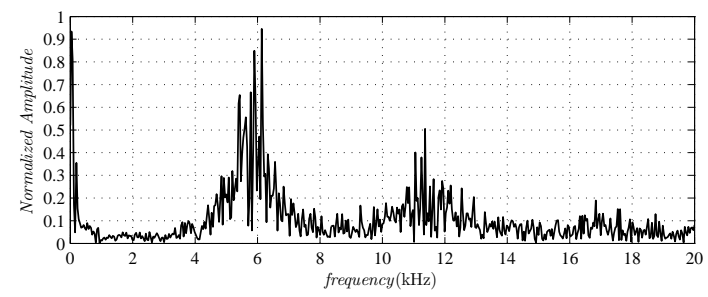

Fig. 12. Switching signal spectrum

\section{E. Switching spectrum}

In Fig. 12 the control signal spectrum is shown. Note that the spectrum is concentrated around $6 \mathrm{kHz}$, as desired by using the switching decision algorithm presented in [24].

\section{CONCLUSIONS}

In this paper a sliding-mode observer-based control for grid-connected LCL-filtered three-phase inverter is proposed. The control algorithm is based on SMC in combination with a KF. This proposal allows to obtain three decoupled controllers which, provides a desired dynamics to the grid-side current. The proposed control technique also improves the tracking performance of the reference and also increases the robustness against grid inductance variation. Theoretical and experimental results show that with this controller no physical damping resistors are needed reducing the control losses. In addition a sinusoidal third harmonic voltage can be injected at the neutral point increasing the control dynamic range. The system stability analysis has been also performed allowing to find the main control parameters.

\section{REFERENCES}

[1] M. Liserre, R. Teodorescu, and F. Blaabjerg, "Stability of photovoltaic and wind turbine grid-connected inverters for a large set of grid impedance values," IEEE Trans. Power Electron., vol. 21, no. 1, pp. 263-272, 2006.

[2] Z. Xu and M. Rahman, "Comparison of a sliding observer and a kalman filter for direct-torque-controlled IPM synchronous motor drives," IEEE Trans. Ind. Electron., vol. 59, no. 11, pp. 4179-4188, Nov 2012.
[3] J. Zhang, M. Lyu, T. Shen, L. Liu, and Y. Bo, "Sliding mode control for a class of nonlinear multi-agent system with timedelay and uncertainties," IEEE Trans. on Ind. Electron., In press.

[4] Z. Chen, "PI and sliding mode control of a cuk converter," IEEE Trans. Power Electron., vol. 27, no. 8, pp. 3695-3703, Aug 2012.

[5] H. Komurcugil, S. Ozdemir, I. Sefa, N. Altin, and O. Kukrer, "Sliding-mode control for single-phase grid-connected LCL filtered vsi with double-band hysteresis scheme," IEEE Trans. Ind. Electron., vol. 63, no. 2, pp. 864-873, Feb 2016.

[6] R. Guzman, L. G. de Vicua, J. Morales, M. Castilla, and J. Miret, "Model-based active damping control for three-phase voltage source inverters with LCL filter," IEEE Trans. on Power Electron., vol. 32, no. 7, pp. 5637-5650, July 2017.

[7] S. Rahmani, A. Hamadi, and K. Al-Haddad, "A LyapunovFunction-Based control for a three-phase shunt hybrid active filter," IEEE Trans. Ind. Electron., vol. 59, no. 3, pp. 14181429, March 2012.

[8] J. Liu, H. Li, and Y. Deng, "Torque ripple minimization of pmsm based on robust ilc via adaptive sliding mode control," IEEE Trans. on Power Electron., In press.

[9] R. Ling, D. Maksimovic, and R. Leyva, "Second-order slidingmode controlled synchronous buck DC-DC converter," IEEE Trans. on Power Electron., vol. 31, no. 3, pp. 2539-2549, March 2016.

[10] R. Padilha Vieira, M. Stefanello, R. Varella Tambara, and H. Grundling, "Sliding mode control in a multi-loop framework for current control of a grid-tied inverter via LCL-filter," in Ind. Electron. Society, IECON 2014 - 40th Annual Conference of the IEEE, Oct 2014, pp. 4384-4389.

[11] I. Boiko, L. Fridman, A. Pisano, and E. Usai, "Analysis of chattering in systems with second-order sliding modes," IEEE Trans. Automatic Control, vol. 52, no. 11, pp. 2085-2102, Nov 2007.

[12] Y. He, H.-H. Chung, C.-M. Ho, and W. Wu, "Use of boundary control with second-order switching surface to reduce the system order for deadbeat controller in grid-connected inverter," IEEE Trans. Power Electron., vol. 31, no. 3, pp. 2638-2653, March 2016.

[13] J. Fei and C. Lu, "Adaptive sliding mode control of dynamic systems using double loop recurrent neural network structure," IEEE Trans. on Neural Networks and Learning Systems, In press.

[14] D. Pan, X. Ruan, C. Bao, W. Li, and X. Wang, "Optimized controller design for LCL-type grid-connected inverter to achieve high robustness against grid-impedance variation," IEEE Trans. on Ind. Electron., vol. 62, no. 3, pp. 1537-1547, March 2015.

[15] L. Zhou, Y. Chen, A. Luo, J. M. Guerrero, X. Zhou, Z. Chen, and $\mathrm{W}$. $\mathrm{Wu}$, "Robust two degrees-of-freedom single-current control strategy for LCL-type grid-connected DG system under grid-frequency fluctuation and grid-impedance variation," IET Power Electron., vol. 9, no. 14, pp. 2682-2691, 2016.

[16] Z. Xin, X. Wang, P. C. Loh, and F. Blaabjerg, "Grid-currentfeedback control for LCL-filtered grid converters with enhanced stability," IEEE Trans. on Power Electron., vol. 32, no. 4, pp. 3216-3228, April 2017.

[17] J. He, Y. W. Li, D. Xu, X. Liang, B. Liang, and C. Wang, "Deadbeat weighted average current control with corrective feed-forward compensation for microgrid converters with nonstandard LCL filter," IEEE Trans. on Power Electron., vol. 32, no. 4, pp. 2661-2674, April 2017.

[18] A. Ghoshal and V. John, "Active damping of LCL filter at low switching to resonance frequency ratio," IET Power Electron., vol. 8, no. 4, pp. 574-582, 2015.

[19] M. Castilla, J. Miret, J. Matas, L. G. de Vicuna, and J. M. Guerrero, "Control design guidelines for single-phase grid- 
connected photovoltaic inverters with damped resonant harmonic compensators," IEEE Trans. on Ind. Electron., vol. 56, no. 11, pp. 4492-4501, Nov 2009.

[20] R. Guzman, L. Garcia de Vicuna, A. Camacho, J. Matas, M. Castilla, and J. Miret, "Active damping control for a three phase grid-connected inverter using sliding mode control," in Ind. Electron. Society, IECON 2013 - 39th Annual Conference of the IEEE, Nov 2013, pp. 382-387.

[21] J. Hung, W. Gao, and J. Hung, "Variable structure control: a survey," IEEE Trans. Ind. Electron., vol. 40, no. 1, pp. 2-22, 1993.

[22] J. M. Kanieski, R. Cardoso, H. Pinheiro, and H. A. Grndling, "Kalman filter-based control system for power quality conditioning devices," IEEE Trans. Ind. Electron., vol. 60, no. 11, pp. 5214-5227, Nov 2013.

[23] M. S. Grewal and A. P. Andrews, Kalman Filtering: Theory and practice using MATLAB. John Wiley \& Sons inc., 2001.

[24] R. Guzman, L. Garcia de Vicuna, J. Morales, M. Castilla, and J. Matas, "Sliding-mode control for a three-phase unity power factor rectifier operating at fixed switching frequency," IEEE Trans. Power Electron., vol. 31, no. 1, pp. 758-769, Jan 2016.

[25] M. Castilla, L. Garcia de Vicuna, J. Guerrero, J. Matas, and J. Miret, "Sliding-mode control of quantum series-parallel resonant converters via input-output linearization," IEEE Trans. Ind. Electron., vol. 52, no. 2, pp. 566-575, April 2005.

[26] X. Bao, F. Zhuo, Y. Tian, and P. Tan, "Simplified feedback linearization control of three-phase photovoltaic inverter with an LCL filter," IEEE Trans. Power Electron., vol. 28, no. 6, pp. 2739-2752, June 2013.

[27] J. Matas, L. de Vicuna, J. Miret, J. Guerrero, and M. Castilla, "Feedback linearization of a single-phase active power filter via sliding mode control," IEEE Trans. Power Electron., vol. 23, no. 1, pp. 116-125, Jan 2008.

[28] Q. Ha, H. Trinh, H. Nguyen, and H. D. Tuan, "Dynamic output feedback sliding-mode control using pole placement and linear functional observers," IEEE Trans. Ind. Electron., vol. 50, no. 5, pp. 1030-1037, Oct 2003.

[29] Y. Liu, W. Wu, Y. He, Z. Lin, F. Blaabjerg, and H.-H. Chung, "An efficient and robust hybrid damper for LCL - or LLCL based grid-tied inverter with strong grid-side harmonic voltage effect rejection," IEEE Trans. Ind. Electron., vol. 63, no. 2, pp. 926-936, Feb 2016.

[30] E. Figueres, G. Garcera, J. Sandia, F. Gonzalez-Espin, and J. Rubio, "Sensitivity study of the dynamics of three-phase photovoltaic inverters with an LCL grid filter," IEEE Trans. Ind. Electron., vol. 56, no. 3, pp. 706-717, 2009.

[31] P. Rodriguez, A. Luna, I. Candela, R. Mujal, R. Teodorescu, and F. Blaabjerg, "Multiresonant frequency-locked loop for grid synchronization of power converters under distorted grid conditions," IEEE Trans. Ind. Electron., vol. 58, no. 1, pp. 127138, Jan 2011.

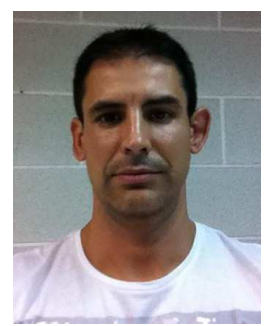

Ramon Guzman received the B.S., the M.S. and the Ph.D. degrees in telecommunications engineering from the Technical University of Catalonia, Barcelona, Spain, in 1999, 2004 and 2016, respectively. $\mathrm{He}$ is currently an Associate Professor with the Department of Automatic Control in the Technical University of Catalonia. His research interests include nonlinear and adaptive control for three-phase

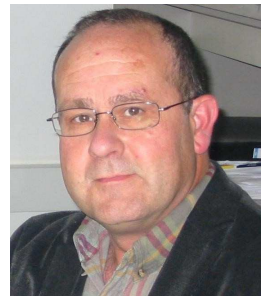

Luis Garcia de Vicuña a received the M.S. and $\mathrm{Ph} . \mathrm{D}$. degrees in telecommunication engineering from the Technical University of Catalonia, Barcelona, Spain, in 1980 and 1990, respectively, and the Ph.D. degree in electrical engineering from the Paul Sabatier University, Toulouse, France, in 1992. From 1980 to 1982 , he was an Engineer with a control applications company in Spain. He is currently a Full Professor with the Department of Electronic Engineering, Technical University of Catalonia, where he teaches courses on power electronics. His research interests include power electronics modeling, simulation and control, active power filtering, and highpower-factor ac/dc conversion.

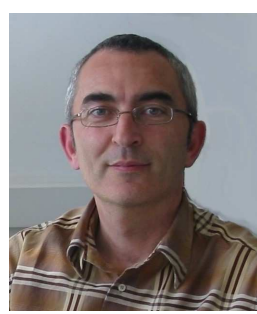

Miguel Castilla received the B.S., M.S., and $\mathrm{Ph} . \mathrm{D}$. degrees in telecommunication engineering from the Technical University of Catalonia, Barcelona, Spain, in 1988, 1995, and 1998, respectively. Since 2002, he has been an Associate Professor with the Department of Electronic Engineering, Technical University of Catalonia, where he teaches courses on analog circuits and power electronics. His research interests include power electronics, nonlinear control, and renewable energy systems.

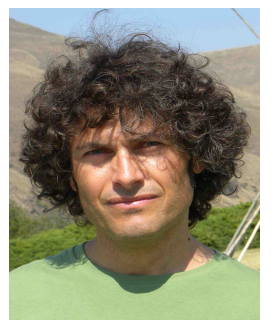

Jaume Miret (M98) received the B.S. degree in telecommunications, M.S. degree in electronics, and Ph.D. degree in electronics from the Universitat Politecnica de Catalunya, Barcelona, Spain, in 1992, 1999, and 2005, respectively. From 1993 to 2011, he was an Assistant Professor in the Department of Electronic Engineering, Universitat Politecnica de Catalunya, Spain. Since 2011 he has been an Associate Professor in the Universitat Politecnica de Catalunya. His research interests include dc-to-ac converters, active power filters, and digital control.

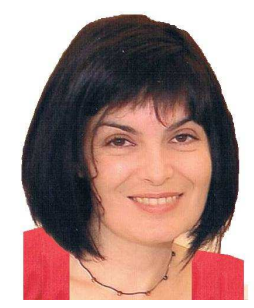

Helena Martín received the B.Sc. degree in Electronic Engineering in 1994, M.Sc. in Electrical Engineering in 1997, Ph.D in Industrial Engineering in 2007. She is currently an Associate Professor with the Department of Electric Engineering in the Technical University of Catalonia Her research interests are optimal management and energy policy for microgids with renewable energy generation. 